
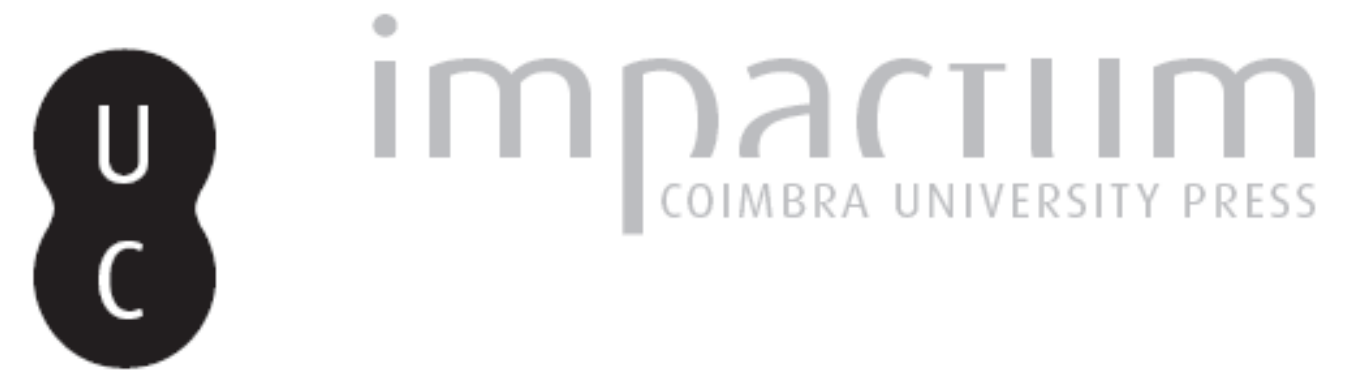

\title{
Modernização administrativa e gestão da qualidade: um estudo empírico nos municípios portugueses
}

Autor(es): $\quad$ Sá, Patrícia Moura e; Sintra, Olívia Fernandes

Publicado por: Faculdade de Economia da Universidade de Coimbra

URL persistente:

URI:http://hdl.handle.net/10316.2/26054

DOI:

DOI:http:/dx.doi.org/10.14195/2183-203X_27_4

Accessed : $\quad$ 26-Apr-2023 15:20:04

A navegação consulta e descarregamento dos títulos inseridos nas Bibliotecas Digitais UC Digitalis, UC Pombalina e UC Impactum, pressupõem a aceitação plena e sem reservas dos Termos e Condições de Uso destas Bibliotecas Digitais, disponíveis em https://digitalis.uc.pt/pt-pt/termos.

Conforme exposto nos referidos Termos e Condições de Uso, o descarregamento de títulos de acesso restrito requer uma licença válida de autorização devendo o utilizador aceder ao(s) documento(s) a partir de um endereço de IP da instituição detentora da supramencionada licença.

Ao utilizador é apenas permitido o descarregamento para uso pessoal, pelo que o emprego do(s) título(s) descarregado(s) para outro fim, designadamente comercial, carece de autorização do respetivo autor ou editor da obra.

Na medida em que todas as obras da UC Digitalis se encontram protegidas pelo Código do Direito de Autor e Direitos Conexos e demais legislação aplicável, toda a cópia, parcial ou total, deste documento, nos casos em que é legalmente admitida, deverá conter ou fazer-se acompanhar por este aviso.

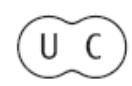




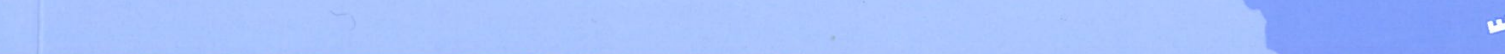

\section{N $\odot$ I $A$ S G O N}

\section{CARLOS BASTIEN/ ANTÓNIO OLIVEIRA MARRECA: UM ECONOMISTA NO PARLAMENTO CECILIA CAMPOS}

\section{DAN LI/}

MANUEL PORTUGAL FERREIRA

INTERNAL AND EXTERNAL FACTORS ON FIRM'S TRANSFER PRICING DECISIONS: INSIGHTS FROM ORGANIZATION STUDIES

CARLOS F. ALVES

O EFEITO DA FAMILIA JURIIDICA NA TRANSPOSIÇÃO DA DIRECTIVA DAS OFERTAS PÚBLICAS DE AQUISIÇÃO

PATRICIA MOURA E SÁ/ OLIVIA FERNANDES SINTRA
MODERNIZAÇÃO ADMINISTRATIVA E GESTÃO DA QUALIDADE: UM ESTUDO EMPÍRICO NOS MUNICÍPIOS PORTUGUESES

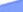
$-$ 4

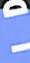




\section{Modernização administrativa e gestão da qualidade:} um estudo empírico nos municípios portugueses
Os esforços de Modernização

Administrativa têm-se norteado por objectivos de simplificação, eficiência e transparência, no sentido de prestar melhores serviços aos cidadãos.

Abordagens de Gestão da Qualidade, centradas em princípios de enfoque no cliente, envolvimento e melhoria contínua, têm vindo a ser encaradas como um veículo para alcançar essas metas. Neste estudo, com dados de 115 municípios portugueses, é feita uma avaliação do estado de implementação de um conjunto de aspectos da Modernização Administrativa e analisada a sua relação com a adopção de referenciais da qualidade. Os resultados permitem afirmar que existem aspectos consagrados em Lei ainda não totalmente implementados e também que os municípios que adoptam a Gestão da Qualidade e, em particular, têm serviços certificados são aqueles em que a Modernização Administrativa está mais avançada, nomeadamente quanto às iniciativas de Governo Electrónico.
Les efforts de Modernisation Administrative ont été dictés par des objectifs de simplification, d'efficacité et de transparence visant à une meilleure qualité des services rendus aux citoyens. Des tentatives de Gestion de la Qualité, centrées sur des principes de valorisation du client, d'engagement et d'amélioration continue, ont été considérées comme un tremplin pour atteindre ces objectifs. Dans cette étude, et sur la base de données concernant 115 municipalités portugaises, on a procédé à une évaluation de l'état de mise en oeuvre d'un ensemble d'aspects de la Modernisation Administrative ainsi qu'à une analyse de leur relation avec l'adoption de référentiels de la qualité. Les résultats permettent d'affirmer qu'il existe des aspects consacrés par la Loi qui ne sont pas encore totalement mis en oeuvre; on peut constater également que les municipalités ayant adopté la Gestion de la Qualité et qui ont, en particulier, des services certifiés, sont celles pour lesquelles la Modernisation Administrative est la plus avancée, notamment en ce qui concerne les initiatives de gouvernement électronique.

Administrative modernisation efforts have been directed towards the goals of simplification, efficiency and transparency, with the aim of providing citizens with higher quality services. Quality Management approaches, based on the principles of customer focus, involvement and continuous improvement, have been regarded as a means to achieve those purposes. In this study, based on data collected from 115 Portuguese municipalities, it is assessed at what extent some administrative modernisation measures are in place and analysed its relationship with the implementation of quality management frameworks. Findings reveal that not only there are several issues established by law not fully implemented, but also municipalities that adopt quality management approaches and, in particular, that have services certified are indeed ahead in the modernisation process, including E-Government initiatives. 
Na generalidade dos países desenvolvidos, tem-se vindo a assistir, nas últimas décadas, a transformações profundas nas Administrações Públicas, fundamentalmente associadas ao abandono de modelos de gestão burocráticos e à sua substituição por um novo paradigma, assente essencialmente na orientação dos serviços públicos para os cidadãos/clientes (Parker e Bradley, 2000; Lawton e Rose, 1991).

Independentemente das diferenças no cariz das reformas, decorrentes de contextos nacionais e institucionais distintos (Guyomarch, 1999), separando fundamentalmente países que seguem o modelo continental daqueles que seguem o modelo anglo-saxónico, é possível identificar um corpo relativamente consistente de elementos comuns a todas elas (Araújo, 1999; Friedrieckson, 1996; Hood, 1995). Deste corpo fazem parte, tal como identificado por vários autores, uma maior orientação para o cliente, o desenvolvimento de novas formas de prestação dos serviços, a adopção de novas tecnologias e o aumento dos mecanismos de prestação de contas centrados nos resultados. Simultaneamente, as reformas têm sistematicamente surgido num contexto de pressão para uma maior parcimónia na utilização dos recursos e têm resultado na fragmentação da Administração Pública e na implementação de referenciais de medição da performance organizacional.

No âmbito da modernização administrativa, a Qualidade tem sido uma preocupação recorrente dos Governos, tendo estado na base de uma série de iniciativas, entre as quais se destacam as Cartas da Qualidade e os Prémios de Excelência para os Serviços Públicos.

A aposta na Qualidade aparece sistematicamente ligada à procura da conjugação de imperativos de eficácia, eficiência e equidade com a satisfação das necessidades dos clientes, naturalmente muito diversificadas e, não raras vezes, conflituais entre si.

Num momento em que cada vez mais municípios investem recursos na certificação dos seus serviços e se desenvolvem e generalizam novas formas de prestação dos serviços, tirando partido das novas tecnologias de informação e comunicação (TIC), entendemos oportuno efectuar um estudo que avalie o nível de implementação das principais medidas decorrentes da modernização administrativa e analise a sua relação com a adopção da Gestão da Qualidade nos municípios portugueses.

Para concretizar este objectivo, foi elaborado um questionário, ao qual responderam 115 autarquias, tendo sido também consultados e analisados os sites institucionais de todos os municípios.

Este estudo, pela sua abrangência (visando o conjunto dos municípios portugueses) e objectivos, é original e poderá deixar indicações importantes para que as autarquias portuguesas avaliem melhor os esforços dos programas e mecanismos que estão a implementar e potenciem as suas vantagens, no sentido de melhor conhecerem e satisfazerem as necessidades dos cidadãos que servem.

Na próxima secção são apresentados os principais referenciais para a implementação e avaliação da qualidade, sendo alguns de natureza mais genérica e outros especificamente desenvolvidos para as Administrações Públicas. São igualmente discutidas algumas das dificuldades inerentes à implementação da Qualidade Total neste contexto. Em seguida, na secção 3, é em traços gerais caracterizado o processo de Modernização Administrativa em Portugal, destacando-se, a esse respeito, alguns marcos. A secção 4 , dedicada à metodologia, apresenta o modelo de análise proposto neste artigo, fundamenta a hipótese de estudo e caracteriza os instrumentos utilizados na recolha dos dados. Os resultados da pesquisa são apresentados e discutidos na secção 5. Finalmente, a secção 6 apresenta as principais conclusões e implicações do estudo realizado. 

em parte remontem aos princípios da gestão científica dos anos vinte (McAdam, 2000). Desde então a GQT evoluiu de uma perspectiva essencialmente mecanicista, em que a qualidade era olhada como um assunto técnico ligado à produção, para uma visão mais sistémica, a qual considera a Qualidade Total como uma filosofia de gestão, que envolve a organização no seu todo (Dale et al., 1997; Mehra et al. 2001).

Existem na literatura múltiplas definições de GQT, as quais, de uma forma ou de outra, enfatizam a sua natureza abrangente. Uma delas é proposta por Kanji (2002: 2) que afirma que "Total Quality Management is a management philosophy that fosters an organisational culture committed to customer satisfaction through continuous improvement".

Ainda que de forma não explícita, a qualidade está, de há muito, presente nas preocupações das Administrações Públicas. Beltrami (1992, citado em Löffler, 2005) distingue três fases na evolução do entendimento da Qualidade nos serviços públicos: (1) qualidade enquanto respeito a regras e procedimentos (correcção formal, paralela à conformidade técnica na indústria);

(2) qualidade como sinónimo de cumprimento de objectivos (na linha da conformidade ao uso);

(3) qualidade enquanto satisfação dos clientes.

Uma vasta parte da literatura debruça-se sobre as dificuldades da aplicação dos princípios da Qualidade Total na Administração Pública (Dewhurst et al. 1999; Morgan e Murgatroyd, 1994; Rago, 1996; Swiss, 1992). Não cabe neste artigo aprofundar a questão. De referir apenas que, efectivamente, as dificuldades começam, desde logo, na identificação do(s) cliente(s) dos serviços prestados pelas Administrações Públicas (Swiss, 1992). Uma definição estrita de cliente, à semelhança do que acontece no sector privado, limitaria e deixaria de fora muitas situações, nomeadamente porque o conceito de cliente tem, em princípio, subjacente o poder de compra e opção de escolha do mesmo sobre o que quer comprar e onde comprar (Flynn, 1997). Esta condição aplicar-se-ia apenas a uma parte do conjunto de serviços prestados pelas Administrações Públicas. Acresce que o paradigma que está associado aos serviços públicos, para além de implicar a existência de uma multiplicidade de stakeholders (Ancarani e Capaldo, 2002), poderá originar "conflitos" de interesses entre os clientes directos de um serviço e os contribuintes em geral (taxpayers). Estes últimos, embora, por vezes, não usufruindo dos serviços, pagam o mesmo via impostos, o que implica que as organizações tenham obrigações que não se esgotam apenas na satisfação dos clientes imediatos (Gaster, 1995). Paralelamente, por imperativos de equidade, há que definir em muitos serviços públicos padrões de prestação, que podem, de algum modo, ser contraditórios com a adaptação e individualização, inerentes à ideia de enfoque no cliente. Assim, em muitas situações, é necessário preservar o princípio do "bem colectivo" e do acesso universal, o que pode significar a impossibilidade de levar às últimas consequências a individualização (customization) do serviço.

Sem que se ignore os desafios que se colocam na tradução de alguns dos conceitos base da GQT para o domínio dos serviços públicos, mormente reconhecendo que é necessário redefinir o poder conferido aos vários stakeholders (nomeadamente, estando preparado para estimular o empowerment de clientes e funcionários e para aceitar novos processos de decisão e responsabilização), é possível hoje afirmar que predomina uma lógica de validade universal de muitos dos princípios da Qualidade Total. Disso é testemunha o facto da esmagadora maioria dos referenciais para a sua implementação serem genéricos e sofrerem apenas pequenas adaptações ao serem introduzidos no contexto da Administração Pública.

Efectivamente, o modelo CAF (Common Assessment Framework) baseia-se assumidamente no Modelo de Excelência da Fundação Europeia para a Qualidade (EFQM), simplificando-o e ajustando-o em termos de linguagem, e as normas ISO, adoptadas por muitos organismos da Administração Pública, incluindo municípios portugueses, como veremos à frente, são aplicáveis exactamente nos mesmos termos a qualquer organização, seja ela pública ou privada. 
Feito este enquadramento, procede-se em seguida a uma breve revisão dos principais referenciais para a implementação e avaliação da qualidade na Administração Pública. Independentemente da importância de cada organização escolher o modelo de implementação que melhor se adequa às suas características, importa sublinhar que se caminha na evolução dos referenciais para uma certa convergência, como o atesta a revisão feita em 2000 às normas ISO, aproximando-as significativamente dos Modelos de Excelência.

\subsection{As normas ISO 9000}

As normas ISO constituem séries de standards reconhecidos a nível internacional, cujo objectivo é garantir a qualidade, assegurando que a organização dispõe de um sistema da qualidade formalizado e documentado, no âmbito do qual as actividades são planeadas e sistematicamente implementadas de forma a proporcionar confiança adequada de que a entidade está em condições de satisfazer os requisitos da qualidade de forma consistente (NP EN ISO 9000:2000). Sendo universais, as normas ISO são naturalmente aplicáveis a qualquer instituição pública.

A norma ISO 9000:2000 identifica oito princípios de gestão da qualidade, que se apresentam na Figura 1, e que se consideram ser responsáveis pela obtenção de elevados padrões de desempenho. Deste modo, a norma mais do que um mero referencial para a eventual certificação, constitui, se bem aplicada, uma verdadeira ferramenta de melhoria da performance organizacional.

Figura 1 - Princípios de Gestão da Qualidade segundo a norma ISO 9000

\begin{tabular}{|c|c|c|c|c|}
\hline Focalização no cliente & $\Rightarrow$ & & 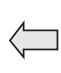 & $\begin{array}{l}\text { Abordagem da gestão } \\
\text { como um sistema }\end{array}$ \\
\hline Liderança & $\Rightarrow$ & $\begin{array}{c}\text { MELHORIA } \\
\text { DESEMPENHO }\end{array}$ & $\Leftrightarrow$ & Melhoria contínua \\
\hline $\begin{array}{l}\text { Envolvimento das } \\
\text { pessoas }\end{array}$ & $\Rightarrow$ & & $\Leftrightarrow$ & $\begin{array}{l}\text { Tomada de decisões } \\
\text { baseada em factos }\end{array}$ \\
\hline $\begin{array}{l}\text { Abordagem por } \\
\text { processos }\end{array}$ & $\Rightarrow$ & & & $\begin{array}{l}\text { Relações mutuamente } \\
\text { benéficas fornecedores }\end{array}$ \\
\hline
\end{tabular}

\section{SATISFAÇÃO DO CLIENTE}

Fonte: Elaboração própria

Em especial, a norma ISO 9004:2000 - Sistemas de gestão da qualidade - Linhas de orientação para melhoria do desempenho - pode ser considerada um guia de auto-avaliação, favorecendo a realização de um diagnóstico interno com a identificação de áreas a melhorar. 
De acordo com as normas, num Sistema de Gestão da Qualidade (ver Figura 2) o cliente é quem "dita" os requisitos que pretende que o produto/serviço contenha, os quais constituem os inputs para o processo. Assim, podemos dizer que o ciclo da melhoria contínua é desencadeado pelo cliente. Paralelamente, para que uma organização saiba se de facto está a cumprir todos os requisitos exigidos pelo cliente, é necessário efectuar a monitorização da sua satisfação, ou seja, é essencial recolher informação sobre a percepção do grau de cumprimento das necessidades e expectativas dos clientes.

\section{Figura 2 - Modelo de um Sistema de Gestão da Qualidade}

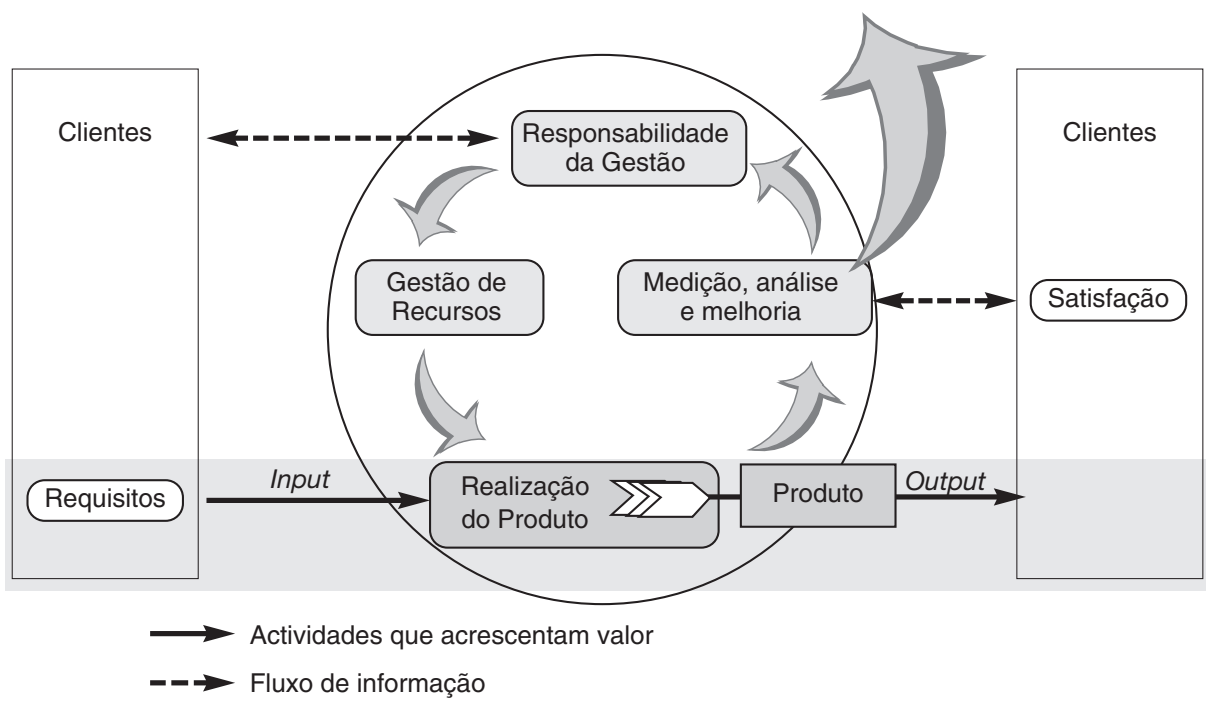

Fonte: NP EN ISO 9000:2000

Para os organismos da Administração Pública, a implementação das ISO pode ser especialmente útil no estabelecimento e avaliação de contratos com fornecedores e parceiros (Löffler, 2005), na medida em que, tal como noutros sectores, as normas funcionam como um alicerce da garantia da qualidade e, portanto, do cumprimento de um certo nível de requisitos.

A implementação de sistemas de gestão da qualidade em linha com as normas ISO 9000 constitui um processo voluntário, assente nas motivações políticas e objectivos intrínsecos a cada organização.

Em Portugal, a certificação de Autarquias Locais (AL) teve o seu início em 2003, com a certificação de serviços dos municípios de Pombal e de Oliveira de Azeméis, sendo actualmente uma realidade em várias Câmaras.

\subsection{O modelo CAF}

Esta ferramenta foi concebida com a finalidade de ser utilizada por todos os sectores da Administração Pública, tendo sido pela primeira vez apresentada na 1. ${ }^{\text {a }}$ Conferência da Qualidade das Administrações Públicas da UE, em Lisboa, em Maio de 2000. 
Tal como o modelo da EFQM, a CAF é composta por nove critérios designados de "meios" e "resultados" (ver Figura 3), sendo que cada critério representa uma dimensão da organização que deverá ser objecto de avaliação. Para cada critério estão definidos subcritérios. A utilização da CAF, como modelo de avaliação organizacional, permite identificar pontos fortes e áreas de melhoria, avaliar o nível de satisfação das diferentes partes que se relacionam com a organização (cidadãos, fornecedores, parceiros e sociedade em geral) e conceber planos de melhoria, alicerçados num diagnóstico amplo e consistente.

\section{Figura 3 - Estrutura Comum de Avaliação}

\section{Estrutura da CAF}

\section{MEIOS}

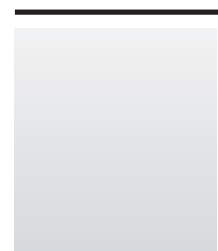

Liderança

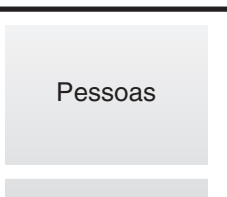

Planeamento

e

Estratégia
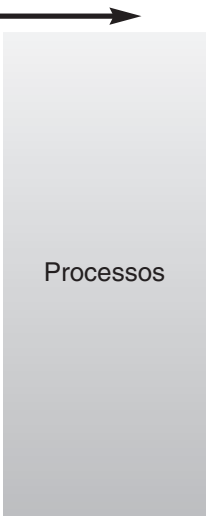

RESULTADOS

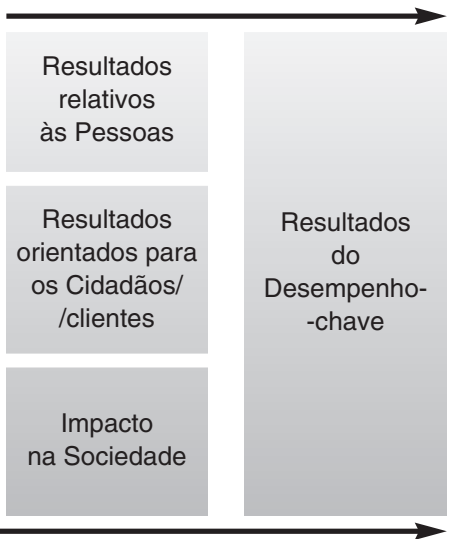

Fonte: Direcção Geral de Administração Pública e do Emprego - www.dgap-gov.pt

No âmbito da CAF, a organização é fortemente incentivada a ouvir os seus clientes e a dar-lhes feedback. Para além do critério - Resultados Orientados para os Cidadãos/Clientes -, as preocupações com os clientes estão presentes na generalidade do modelo. O critério do Planeamento e Estratégia, por exemplo, exige que a organização recolha informação relacionada com as necessidades actuais e futuras dos seus clientes. Também, no âmbito do critério de Parcerias e Recursos, são incentivadas as relações de proximidade com os clientes.

Nalguns países, como é o caso de Portugal, foram desenvolvidas ferramentas e guias de apoio à aplicação da CAF. A este respeito, a Direcção Geral da Administração Pública (DGAP), actualmente DGAEP, publicou em 2004 um manual de aplicação da CAF, que, além da metodologia para os serviços aplicarem a CAF, contempla aspectos considerados críticos para o sucesso da sua aplicação e fornece propostas para o processo de melhoria da organização.

Os números demonstram uma boa adesão a este instrumento. Efectivamente, conforme um estudo realizado pelo European Institut for Public Administration (EIPA), em 2003, isto é três anos depois da sua introdução, existiam já cerca de 500 organizações europeias a aplicar a CAF. Dois anos depois, em 2005, esse número teria crescido, segundo a mesma fonte, para perto das 900 aplicações em 20 países (Staes e Thijs, 2005).

A implementação da CAF nas AL portuguesas tem sido apoiada (em muitos casos) pelo Programa DIQUAL, financiado pela União Europeia, para formação de apoio à implementação 
de Sistemas de Gestão da Qualidade. Dele beneficiaram municípios como o de Pombal, Leiria, Águeda, Coimbra, Aveiro, Porto, Vale de Cambra e Pedrógão Grande, entre outros.

Para divulgar boas práticas e, desse modo, encorajar a aprendizagem e inovação têm sido, em vários países, criados prémios (Löffler, 2005). Em Portugal, a Direcção Geral da Administração Local (DGAL) utiliza os critérios da CAF na selecção das candidaturas ao Concurso de Boas Práticas de Modernização Autárquica. Paralelamente, as organizações que utilizam a CAF e que atingem determinado patamar de pontuação são reconhecidas segundo os níveis do esquema da EFQM.

\subsection{Outros referenciais específicos}

Dada a natureza de uma boa parte das Administrações Públicas, um primeiro conjunto de modelos e referenciais enquadram-se na óptica da medição da qualidade em serviços e no conhecimento dos seus determinantes. Neste âmbito, se inserem sobretudo as múltiplas aplicações do SERVQUAL (proposto por Zeithalm, Berry e Parasuraman, 1988) nos serviços públicos.

De forma mais específica ao sector público, no decurso da década de oitenta, surgiu um interesse em conceber e especificar standards, sobretudo na administração local americana e britânica. Tais standards representam, no fundo, níveis de desempenho dos serviços que, ao serem publicados e divulgados, conferem aos cidadãos que deles beneficiam uma ideia do que podem e devem esperar, podendo assim ser entendidos como uma espécie de contrato entre estes organismos e os cidadãos (Flynn, 1997).

Já na década de noventa, e no seguimento desta tendência, foram publicadas, em diferentes países, as chamadas "Cartas do Cidadão" (Citizen Charters). Estas visam atrair a atenção não só dos gestores e funcionários públicos para a concretização dos padrões estabelecidos, mas também dos clientes quanto às expectativas que estes podem ter em relação aos serviços prestados, aumentando assim a confiança na Administração. Em países de tradição continental (como a França e Portugal, por exemplo), estas Cartas têm como principal intuito melhorar o serviço público a partir de um equilíbrio de direitos e obrigações dos vários stakeholders (Löffler, 2005).

Nalguns países, mormente em Inglaterra, assiste-se ainda à tendência para produzir um conjunto vasto de indicadores de desempenho (alguns directamente ligados a aspectos da qualidade de serviço) como forma de encorajar a comparabilidade, fundamentar decisões de afectação de recursos e promover mecanismos de prestação de contas.

\section{Modernização administrativa em Portugal: principais marcos}

Ao caracterizar-se a Administração Pública em Portugal, e tendo apenas como horizonte de análise o regime democrático do pós 25 de Abril, é possível identificar-se três grandes períodos (Nolasco, 2004).

O primeiro, que decorreu entre 1974 e 1985, é dominado pelas preocupações com a descentralização e desconcentração de competências e com a situação profissional, social e económica dos funcionários. É neste período que surge a Lei de Bases da Reforma Administrativa e que se destacam as ideias de desburocratizar, racionalizar e simplificar. No início da década de oitenta, é feito um esforço claro para melhorar e valorizar os serviços de atendimento e generalizar os serviços de informação ao público. Pela primeira vez aparece explicitamente a palavra modernização, como sendo um dos objectivos do programa de Governo.

Numa segunda fase, correspondente grosso modo ao período 1985-1995, imperam as prioridades decorrentes da tendência internacional vulgarmente designada como Nova Gestão Pública (New Public Management) e que se reflectem na promoção de uma nova cultura 
organizacional, centrada nas necessidades dos clientes da Administração Pública. Nesse âmbito, reforçam-se também as preocupações com a eficiência da gestão pública (Jackson, 1995).

O Secretariado para a Modernização Administrativa (SMA) surge neste período e vem dar um novo impulso às questões da qualidade. São da sua iniciativa medidas como a abertura dos serviços à hora de almoço e a simplificação de formulários e formalidades.

Assim, na Administração Pública portuguesa, a implementação da Gestão da Qualidade inicia-se de forma mais deliberada no princípio dos anos noventa e representa mais um esforço no âmbito da concretização da reforma administrativa, colocando o cidadão como agente impulsionador da mudança e incutindo no mesmo a necessidade de exigir mais e melhor dos serviços públicos. Nesse âmbito, surge em Portugal, em 1993, a primeira Carta da Qualidade. Tratou-se de um passo importante, numa altura em que a Qualidade era um conceito ainda muito conotado com o sector privado. Com esta Carta, o cidadão assumiu pela primeira vez o estatuto de cliente, passando a ser o centro das atenções no serviço público. O Programa da Qualidade, criado no mesmo ano, veio estabelecer três objectivos primordiais: transparência, simplificação e participação (Araújo 2001). Como consta do programa do XII Governo Constitucional, a Qualidade é, nesta fase, entendida como "prestação do serviço eficaz, atendimento humanizado, satisfação atempada e célere das solicitações dos utentes", sendo que a sua medição se faz pela "inexistência de erros, defeitos, reclamações, atrasos e incompreensões".

O último período, que se inicia em meados da década de noventa e que se prolonga até à actualidade, é caracterizado por um alargamento do entendimento da Qualidade e pela introdução em ritmo acelerado das questões relacionadas com o Governo Electrónico.

É nesta altura que a modernização administrativa tem, em Portugal, a sua expressão mais visível com a publicação do DL n.. 135/99 de 22 de Abril, o qual "estabelece medidas de modernização administrativa, designadamente sobre acolhimento e atendimento dos cidadãos em geral e dos utentes económicos em particular, comunicação administrativa, simplificação de procedimentos, audição dos utentes e sistema de informação para a gestão".

Paralelamente, foi instituído, no mesmo ano, o Sistema de Qualidade em Serviços Públicos (SQSP), o qual tem como objectivo não só "incentivar as melhorias de qualidade de prestação dos serviços públicos", com também "institucionalizar uma nova cultura de gestão da Administração Pública", que permitirá "maior eficiência e eficácia dos serviços públicos, a desburocratização e simplificação de processos e procedimentos e a satisfação das necessidades explícitas e implícitas dos cidadãos". A certificação seria, neste âmbito, concedida às organizações que demonstrassem cumprir um certo número de requisitos relacionados com o Modelo da EFQM. Por falta de concretização regulamentar, o SQSP nunca saiu do "papel".

A publicação destes diplomas legais veio, em todo o caso, materializar a preocupação do Estado em orientar os serviços públicos para os seus clientes.

Mais recentemente, reforça-se na Administração Pública a cultura da medição da performance organizacional orientada para os resultados. Disso são exemplo a criação do Sistema Integrado de Avaliação do Desempenho da Administração Pública (SIADAP) (Lei 10/2004) e a promoção da utilização da CAF.

Todos estes passos são acompanhados por um investimento substancial no desenvolvimento da prestação dos serviços online.

Esta tendência portuguesa está em linha com as prioridades internacionais. De facto, a crescente utilização do computador e da Internet tem sido, em termos mundiais, encarada como uma oportunidade a aproveitar pelos organismos públicos, no sentido de disponibilizarem um maior número de serviços via digital, tornando a Administração Pública menos burocrática, mais eficaz, mais rápida e mais próxima do cidadão/utente. 
Ao nível da União Europeia, a temática do Governo Electrónico e a promoção dos seus potenciais benefícios tem sido objecto de muitos relatórios e estudos. Como exemplo deste interesse, foi adoptado em 2002, pelo Conselho Europeu de Barcelona, o plano de acção e-Europe, que considera a disponibilização de informação através da Internet como um objectivo primordial para os países da União Europeia. Posteriormente, em 2005, foi lançado outro plano de acção e-Europe, que visa identificar algumas prioridades, de entre as quais se destaca a generalização da disponibilização da banda larga a todos os serviços públicos, assim como, a existência de um número de postos de acesso gratuito à Internet, necessários para assegurar que todos os cidadãos podem aceder e utilizar os novos canais de comunicação disponibilizados pelo Governo.

Em Portugal, a implementação de acções conducentes à eficiência e qualificação dos serviços prestados, o reforço dos meios de participação dos clientes e a redução de custos aparecem apoiadas numa estratégia de desenvolvimento e implementação do Governo Electrónico, fortemente impulsionada pelo Plano de Acção para a Sociedade de Informação (Resolução do Conselho de Ministros n. $-107 / 2003$, de 26 de Junho). O referido plano pretendeu estabelecer uma estratégia a nível nacional para o Governo Electrónico, consubstanciado num conjunto de acções e projectos agrupados num conjunto de eixos, em que o primeiro é precisamente o de prestar serviços públicos orientados para o cidadão.

Com o Governo Electrónico visa-se, não só aumentar a comodidade dos utentes, demonstrar transparência e reduzir custos, como também contribuir para um maior envolvimento dos cidadãos e, por esta via, para uma cidadania mais activa.

\section{Metodologia}

\subsection{Modelo de análise}

A caracterização do processo de Modernização Administrativa, feita na secção anterior, permite identificar alguns objectivos que são transversais aos vários períodos e que se poderão sintetizar do seguinte modo:

- Simplificação;

- Desburocratização;

- Racionalização;

- Transparência; e

- Orientação dos serviços para os cidadãos.

Da vasta literatura sobre os elementos da Gestão da Qualidade em Serviços (Lacke e Mohanty, 1995; Robledo, 2001; Silvestro, 2001; Soteriou e Chase, 1998; Sureshandar et al., 2001), é, entretanto, possível extrair os seguintes princípios fundamentais:

- Enfoque no Cliente;

- Constância de Propósito (liderança e visão);

- Gestão de Processos;

- Excelência dos Recursos Humanos;

- Gestão baseada em factos;

- Benchmarking;

- Melhoria contínua; e

- Servicescapes (tangíveis). 
Não é difícil verificar que estes elementos correspondem, grosso modo, aos princípios genéricos da Gestão da Qualidade segundo as normas ISO e se traduzem, em boa medida, nos critérios dos modelos de excelência, abordados na secção 2. Convém, ainda assim, sublinhar a importância da presença dos tangíveis, que representam os elementos mais "palpáveis" que rodeiam os serviços (instalações, formulários, aparência e apresentação dos funcionários de contacto, etc.).

Da revisão feita anteriormente, terá ficado claro que a implementação da Gestão da Qualidade na Administração Pública, nomeadamente ao encorajar a constância de propósito, a excelência dos processos e a gestão baseada em factos, visa principalmente:

- Melhorar a performance das organizações públicas;

- Tornar as organizações mais responsáveis perante os cidadãos; e

- Aumentar a satisfação dos cidadãos com os serviços prestados.

Assim, como referido por Hyde (1992), a GQT é entendida pelos governos em múltiplos países, como indispensável aos processos de modernização das Administrações Públicas.

Por outro lado, a generalidade das medidas de modernização administrativa está em consonância com alguns princípios da Qualidade Total ao reforçar (Gaster, 1996):

- A flexibilidade e capacidade de resposta às necessidades locais;

- A simplicidade de acesso;

- O empowerment e auto-controlo;

- A coordenação e o desenvolvimento de parcerias; e

- A partilha de informação e a capacidade de decisão.

Assim, é possível afirmar que ao enfatizar os princípios de descentralização, autonomia, simplificação e desenvolvimento de parcerias, pelo menos no plano teórico, a Modernização Administrativa pode contribuir para a introdução e difusão de alguns princípios da GQT na Administração Pública (Sá, 2002), sobretudo ao nível da gestão de processos e enfoque no cliente.

Tendo em conta a semelhança dos objectivos e a compatibilidade de abordagens, tal como sugerido na Figura 4, é proposta uma relação de reforço positivo entre a implementação da Gestão da Qualidade e a concretização da Modernização Administrativa, o que dá origem à seguinte hipótese de pesquisa:

- Os municípios que implementam a Gestão da Qualidade estão mais avançados no processo de Modernização Administrativa, em relação àqueles que não adoptam os referenciais da Qualidade. 


\section{Figura 4 - Modelo de análise}

\section{GESTÃO DA QUALIDADE EM SERVIÇOS}

Princípios fundamentais

- Enfoque no Cliente

- Constância de Propósito (liderança e visão)

- Gestão de Processos

- Excelência dos Recursos Humanos

- Gestão baseada em factos

- Benchmarking

- Melhoria contínua

- Servicescapes (tangíveis)

\section{Estratégias}

- Medição e avaliação

- Formação

- Trabalho em equipa

- Empowerment

- Ciclo PDCA

-...

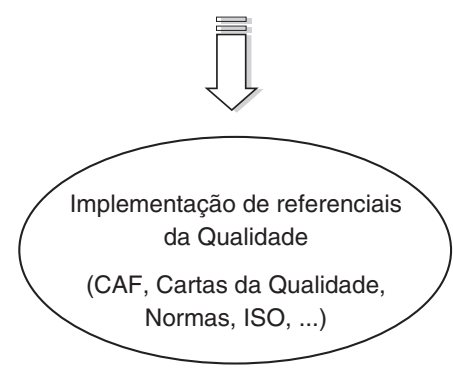

Fonte: Elaboração própria

\section{MODERNIZAÇÃO ADMINISTRATIVA}

Princípios fundamentais

- Desburocratização

- Transparência

- Racionalidade

- Simplicidade

- Eficiência

- Acesso

- Flexibilidade

\section{Estratégias}

- Qualificação dos recursos humanos

- Descentralização

- Orientação dos serviços para o cidadão

- Medição da performance

$\bullet .$.

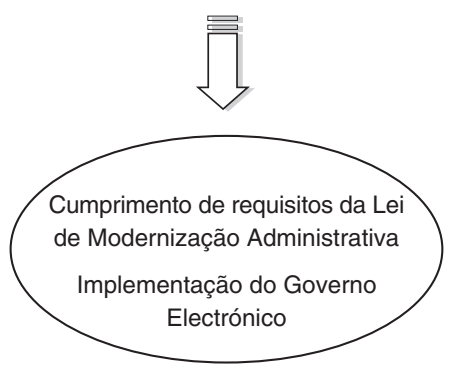

Para operacionalizar o modelo de análise, os municípios foram classificados em dois grupos, consoante tivessem implementado ou não pelo menos um dos referenciais da qualidade identificados (nomeadamente tivessem serviços certificados, usassem a CAF ou tivessem sido distinguidos com algum prémio referente à qualidade dos seus serviços). Paralelamente, e no que se refere à Modernização Administrativa, consideraram-se dois aspectos fundamentais: o cumprimento de alguns requisitos do DL. 135/99 e o nível de implementação do Governo Electrónico aferido a partir da análise dos sites institucionais dos municípios na Internet. 
4.2. Instrumentos de recolha de dados

Com o objectivo de avaliar o grau de implementação de um conjunto de mecanismos preconizados no DL no 135/99 e analisar a sua relação com a adopção da Gestão da Qualidade foi elaborado um questionário, o qual foi administrado, primeiro via e-mail e posteriormente via postal, à totalidade dos municípios portugueses.

As questões apresentadas foram divididas por cinco secções, designadamente:

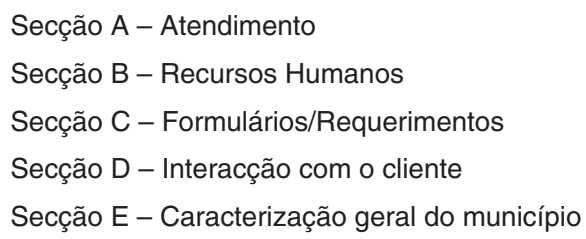

No que respeita ao atendimento, atendeu-se em especial aos seguintes itens:

- Existência ou não de um horário de atendimento contínuo; e

- Condições da recepção ou "espaço principal de acolhimento".

Na secção de recursos humanos, inquiriram-se os municípios sobre:

- O número, qualificação e formação dos seus funcionários, em especial daqueles que estão ligados às actividades de contacto com os cidadãos/clientes; e

- Processos de selecção e integração de novos funcionários.

Relativamente aos formulários e requerimentos, foram considerados os seguintes aspectos:

- Instruções de preenchimento; e

- Qualidade da informação recolhida.

A interacção com o munícipe tratou fundamentalmente os seguintes elementos:

- Formas de divulgação de informação aos cidadãos/clientes;

- Diversidade e funcionamento dos mecanismos de audição e participação dos cidadãos/clientes;

- Medição da satisfação dos cidadãos/clientes;

- Comunicação interna dos elementos recolhidos; e

- Mecanismos de transmissão de feedback aos cidadãos/clientes.

Finalmente, na secção dedicada à caracterização geral do município, para além de alguns dados estatísticos relativos ao número de funcionários e número médio de atendimentos semanais, as câmaras foram inquiridas a respeito dos referenciais da Gestão da Qualidade implementados, maturidade dessas iniciativas e abrangência das mesmas.

Durante o mês de Abril de 2005 foi efectuado um teste piloto a 20 municípios, com o objectivo de validar (e melhorar) o questionário. Posteriormente, em Maio, o questionário final foi enviado aos municípios portugueses, fazendo-se acompanhar de uma carta de apresentação. 
Nesta primeira fase foram recebidos 65 questionários preenchidos. Numa segunda fase, em Setembro de 2005, e com o objectivo de melhorar a taxa de resposta, voltou-se a enviar o questionário por correio a 60 municípios escolhidos aleatoriamente, tendo sido também efectuada uma insistência via e-mail junto dos restantes não respondentes. Nesta fase, obteve-se a resposta de mais 50 municípios.

O questionário foi dirigido aos Presidentes de Câmara, atendendo a que o mesmo abrangia a descrição e avaliação de um conjunto bastante diversificado de áreas. Na maioria dos casos, os questionários foram preenchidos por Chefes de Divisão, ou por um colaborador designado por estes.

Para avaliação do nível de implementação do Governo Electrónico, foram analisadas, em final de 2006, as páginas institucionais de todos os municípios portugueses, tendo-se para o efeito utilizado a escala proposta pelo programa e-Europe, o qual sugere cinco níveis distintos, correspondentes a diferentes graus de maturidade:

- Nível 0 - Ausência de web site;

- Nível 1 - Informativo;

- Nível 2 - Interacção em sentido único;

- Nível 3 - Interacção bidireccional;

- Nível 4 - Transacção do serviço.

A classificação dos municípios teve por base a elaboração de uma grelha de avaliação contendo os parâmetros subjacentes a cada um dos níveis.

Para que fosse atribuído o nível 1 a um município, foram considerados parâmetros relacionados com a informação genérica disponibilizada através da Internet, nomeadamente referente à estrutura orgânica da autarquia, contactos, informações úteis, links de interesse para o cidadão, divulgação de eventos culturais, publicações, legislação, mapas do site, newsletter e envio e recepção de mensagens de correio electrónico.

No nível 2 ficaram incluídos os municípios que para além de disponibilizarem as informações referidas no nível 1, oferecessem também a possibilidade de se fazer download de formulários e das respectivas instruções de preenchimento.

O nível 3 foi atribuído aos municípios em que o site adicionalmente permite uma interacção entre o cliente e a autarquia. Aqui, enquadra-se a faculdade não só de poder preencher os formulários electronicamente, recorrendo à autenticação física ou legal do requerente, mas também a possibilidade de consulta online de processos. Neste nível foram também considerados parâmetros como a existência de mecanismos de recolha de sugestões e /ou reclamações e fóruns online.

Por fim, o nível 4 foi conferido aos municípios cuja página internet disponibilizasse aos seus utilizadores um conjunto de funcionalidades que permitissem realizar por completo uma transacção, incluindo, portanto, a recepção/submissão, tratamento, decisão, entrega e pagamento (com segurança) online do serviço pretendido. De realçar que a este nível também se encontra associada a não existência de qualquer documento em suporte de papel.

\section{Apresentação e discussão dos resultados}

Do universo dos 308 municípios, 115 responderam ao questionário, o que corresponde a uma taxa de $37 \%$ (veja-se a Tabela 1). Atendendo ao número de respostas obtidas em estudos semelhantes, podemos considerar que a adesão a este inquérito foi significativa. 
Tabela 1 - Taxas de resposta

\begin{tabular}{lcccc} 
& Municípios inquiridos & Respostas obtidas & Taxa de resposta \\
\hline Continente & 278 & 107 & $38,4 \%$ \\
\hline Madeira & 11 & 2 & $18,2 \%$ \\
\hline Açores & 19 & 3 & $15,8 \%$ \\
\hline Total & 308 & 115 & $37 \%$
\end{tabular}

Adicionalmente, verifica-se que, dos 115 municípios respondentes, 67 (isto é, mais de metade) afirmam implementar referenciais de Gestão da Qualidade (normas ISO, CAF, Cartas da Qualidade e, residualmente, outros). Destes, e segundo informações actualizadas a Março de 2008, tendo por base a consulta dos sites dos próprios municípios e de entidades certificadoras e consultoras a prestar serviços para a Administração Pública, constata-se que 28 têm um ou mais serviços certificados (a certificação integral é ainda rara). A Tabela 2 resume este panorama, o qual comparado com o estudo realizado por Sá (2002) permite constatar que a implementação da Qualidade nos municípios portugueses subiu, entre 2000 e 2006, de 33\% para $58 \%$ e que a certificação, em particular, sofreu um aumento exponencial (de pouco mais de 4\% em 2000 para 24\% no início de 2008).

\section{Tabela 2 - Implementação da Qualidade}

\begin{tabular}{lc} 
Municípios a implementar referenciais da Qualidade (MQUAL) & $67(58 \%)$ \\
\hline Municípios com serviços certificados (CERT) & $28(24 \%)$ \\
\hline Municípios não certificados (NAOC) & $39(34 \%)$ \\
\hline Municípios que não implementam referenciais da Qualidade (MSEM) & $38(33 \%)$ \\
\hline Não respondem (NR) & $10(9 \%)$ \\
\hline Total & $115(100 \%)$ \\
\hline
\end{tabular}

\subsection{Caracterização do atendimento e acolhimento aos clientes nos municípios}

Como forma de prestar os primeiros esclarecimentos e/ou efectuar um encaminhamento dos clientes para o serviço/departamento adequado, as autarquias deverão possuir na entrada uma zona de atendimento, onde deve permanecer um colaborador conhecedor da estrutura da organização que integra e com formação na área de atendimento ao público, tal como referido

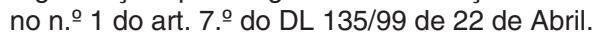

No estudo realizado, observa-se que 90 dos 115 municípios que responderam ao questionário possuem de facto uma zona de atendimento principal ou recepção e que em $90 \%$ dos municípios os colaboradores do atendimento são conhecedores da estrutura e das competências da organização.

Este aspecto deixa antever desde logo uma preocupação com o acolhimento ao cliente quando este "chega" à organização e constitui um primeiro passo importante para prestar serviços com qualidade.

Tendo em conta a importância das condições físicas e operacionais em que o atendimento decorre, incluiu-se no questionário uma pergunta com alguns parâmetros sobre os locais de atendimento, cujos resultados se apresentam na Tabela 3. 


\begin{tabular}{|c|c|c|c|c|c|c|c|c|}
\hline & \multicolumn{2}{|c|}{ Muito Bom } & \multicolumn{2}{|c|}{ Bom } & \multicolumn{2}{|c|}{ Razoável } & \multicolumn{2}{|c|}{ Mau } \\
\hline & N.우 & $\%$ & N.ㅇ & $\%$ & N.ㅇ & $\%$ & NN. & $\%$ \\
\hline Luminosidade & 46 & 41 & 54 & 48 & 12 & 11 & 1 & 1 \\
\hline Temperatura & 26 & 23 & 56 & 50 & 26 & 23 & 5 & 4 \\
\hline Mobiliário & 29 & 26 & 59 & 52 & 25 & 22 & 0 & 0 \\
\hline Equipamento Informático & 33 & 29 & 57 & 50 & 21 & 19 & 2 & 2 \\
\hline
\end{tabular}

Com base nos resultados obtidos, podemos afirmar que, de uma maneira geral, as autarquias avaliam positivamente as condições dos locais de atendimento, o que indicia que os municípios têm vindo a adaptar gradualmente as suas infra-estruturas com o objectivo de proporcionar aos funcionários de contacto (i.e. àqueles que directamente lidam com o público) condições de trabalho que Ihes permitam prestar um serviço público de qualidade.

Adicionalmente, cerca de três quartos das autarquias avaliou favoravelmente o nível de conforto geral das instalações.

O horário de atendimento constitui cada vez mais um factor a ter em conta para a adequação do serviço às necessidades do cliente, tendo por isso sido incluído no DL 135/99.

A este respeito, observa-se que 56 dos 115 municípios, possuem horário de atendimento contínuo (sem interrupção à hora de almoço), dando assim cumprimento ao disposto no n. $\stackrel{0}{1}$ do art. $5^{\circ}$ do diploma legal anteriormente referido. Consequentemente, $51 \%$ dos municípios está ainda numa situação de incumprimento neste tocante.

Uma outra imposição do referido decreto-lei tem a ver com a obrigatoriedade da identificação dos colaboradores que prestam atendimento. Neste concernente, menos de metade dos municípios cumprem com o estabelecido, o que constitui um "ponto negro" para a qualidade do serviço.

Ao mesmo tempo, é interessante avaliar até que ponto as câmaras que implementam referenciais da Qualidade se distinguem das restantes no cumprimento destes requisitos. A Tabela 4 sintetiza esta comparação.

\begin{tabular}{l|c|c|c|c|}
\hline Tabela 4 - Análise comparativa do nível de cumprimento dos requisitos de atendimento \\
\hline \multirow{2}{*}{ Parâmetro } & GLOBAL & MSEM & \multicolumn{3}{c|}{ MQUAL } \\
\cline { 4 - 5 } & & & NAOC & CERT \\
\hline Zona de atendimento & $78 \%$ & $60 \%$ & $85 \%$ & $96 \%$ \\
\hline Horário Contínuo & $49 \%$ & $42 \%$ & $51 \%$ & $50 \%$ \\
\hline Identificação dos funcionários do atendimento & $49 \%$ & $44 \%$ & $54 \%$ & $46 \%$ \\
\hline
\end{tabular}

De facto, o nível de cumprimento nos municípios que implementam a Qualidade é sistematicamente superior, sobretudo no que diz respeito à existência de uma zona de atendimento, sendo particularmente expressiva em caso de certificação. Ainda assim, mesmo nas autarquias com serviços certificados, o horário contínuo estava no final de 2005 implementado em apenas metade dos casos. 


\subsection{Recursos humanos}

Da análise aos questionários recebidos, tal como consta da Tabela 5 , há a referir que a grande maioria dos municípios considera suficientes e bem qualificados os recursos humanos de que dispõe para fazer face à prestação de um atendimento de qualidade.

\begin{tabular}{l|c|c}
\hline Tabela 5 - Caracterização dos recursos humanos afectos ao atendimento \\
\hline & $\begin{array}{c}\text { Número de Municípios } \\
\text { que responderam } \\
\text { à questão }\end{array}$ & $\begin{array}{c}\text { Respostas } \\
\text { afirmativas } \\
(\%)\end{array}$ \\
\hline Suficiência de Recursos Humanos & 99 & 84 \\
\hline Recursos Humanos Qualificados & 56 & 90 \\
\hline $\begin{array}{l}\text { Recursos Humanos Conhecedores das Competências } \\
\text { e estrutura da organização }\end{array}$ & 113 & 90 \\
\hline $\begin{array}{l}\text { Detentores de competências no auxilio ao } \\
\text { preenchimento dos requerimentos e/ou formulários }\end{array}$ & 113 & 91 \\
\hline
\end{tabular}

A formação é um factor fundamental para a qualificação de recursos humanos. De acordo com os resultados obtidos, em $94 \%$ dos municípios a formação abrange virtualmente todas as áreas da organização. Quanto aos níveis hierárquicos abrangidos, $98 \%$ responde que a formação contempla todos os níveis. Contudo, apenas em cerca de metade dos municípios é feito o levantamento total das necessidades de formação, sendo que idêntica percentagem refere que esse levantamento é feito parcialmente.

Efectivamente, é imprescindível que a formação ministrada seja avaliada, com o objectivo não só de melhor qualificar os recursos humanos, como também de optimizar os meios financeiros disponíveis para o efeito.

Tabela 6 - Análise comparativa da formação
\begin{tabular}{|l|c|c|c|c|}
\hline \multirow{2}{*}{ Parâmetro } & \multirow{2}{*}{ GLOBAL } & MSEM & \multicolumn{2}{|c|}{ MQUAL } \\
\cline { 4 - 5 } & & & NAOC & CERT \\
\hline Identificação das necessidades de formação & $97 \%$ & $95 \%$ & $92 \%$ & $96 \%$ \\
\hline Avaliação da formação & $42 \%$ & $42 \%$ & $41 \%$ & $48 \%$ \\
\hline
\end{tabular}

Como se observa na Tabela 6, neste caso não é possível encontrar diferenças substanciais entre os municípios. Se a identificação das necessidades de formação é uma prática generalizada, já a avaliação da formação ocorre em menos de $50 \%$ das câmaras, independentemente destas implementarem ou não a referenciais da qualidade e estarem ou não certificadas.

\subsection{Interacção com o cliente}

Um dos veículos basilares para a comunicação entre a autarquia e os seus clientes é proporcionado pelos espaços de acesso público da câmara municipal.

Os resultados indicam que todos os municípios utilizam a área de atendimento principal para afixação de editais e $90 \%$ divulga aí também eventos culturais. Uma percentagem situada entre $50 \%$ e $80 \%$ refere que na zona de atendimento se encontram afixados anúncios de concursos de 
obras públicas, anúncios de concursos de recursos humanos, publicidade a aç̧ões de formação ou seminários, bem como painéis de sinalização de auto encaminhamento.

Entretanto, 94 municípios responderam ter no atendimento um computador com acesso à Internet e/ou INFOCID, o que representa uma percentagem de $84 \%$ no universo dos municípios que participaram no estudo. No entanto, apenas $52 \%$ indica que a sua utilização é frequente.

Os documentos que suportam a prestação do serviço, mais concretamente os formulários e requerimentos, são também factores críticos para a qualidade do serviço. No estudo realizado, $76 \%$ dos municípios afirma que os requerimentos e formulários que utiliza possuem instruções claras de preenchimento. No entanto, $74 \%$ das $A L$ assume que os seus requerimentos não estão aptos a recolher sugestões e comentários dos clientes.

A maioria das autarquias opta por divulgar os seus serviços através da Internet (85\%), boletins $(78 \%)$ e brochuras $(52 \%)$, destacando-se a importância crescente que é dada à divulgação na Internet das actividades dos municípios.

Igualmente importante é conhecer os mecanismos oferecidos para estimular a comunicação no sentido inverso (isto é, dos munícipes para a autarquia). Tal como consta da Tabela 7, o estudo realizado mostra que, de entre os mecanismos propostos, os mais utilizados são as caixas de sugestões/opiniões (48\%), as fichas de atendimento $(26 \%)$, os questionários $(23 \%)$ e as linhas azuis $(22 \%)$.

Tabela 7 - Mecanismos de auscultação dos clientes Mecanismos de recolha de sugestões/opiniões

Caixa de sugestões/opiniões 24

\begin{tabular}{lc}
\hline Ficha de atendimento & 18 \\
\hline Questionários & 13 \\
\hline Comissões de utentes & 0 \\
\hline Sistema de e-referendos & 8 \\
\hline Linhas Azuis & 13 \\
\hline Outro & 5 \\
\hline Não responde & 18 \\
\hline
\end{tabular}

A existência da caixa de sugestões e/ou reclamações ganhou importância com a publicação do DL n. $-135 / 99$ de 22 de Abril, que, no seu art. 36º, identifica a recolha do feedback dos clientes como instrumento institucionalizado de audição dos mesmos e de aferição da qualidade dos serviços públicos prestados.

Para que o enfoque no cliente seja real e se traduza na melhoria dos serviços, é necessário entretanto que o conhecimento recolhido junto dos clientes seja transmitido vertical e horizontalmente por meios formais e informais (Zeithaml et al., 1988), de forma a abranger toda a organização. $O$ inquérito realizado indica que a informação recolhida dos clientes é dada a conhecer ao Presidente de Câmara (62\%), ao restante executivo camarário $(22 \%)$ e aos Directores de Departamento e Chefes de Divisão (59\%). Apenas em 19 municípios a informação é divulgada a todos os colaboradores.

Não podemos deixar de referir que esta é uma lacuna importante, atendendo a que os colaboradores do atendimento, apesar de serem, aos olhos do cliente, os principais intervenientes na prestação do serviço, são aqueles que menos informações recebem quanto à análise do feedback dos clientes. 
No DL n. $135 / 99$ de 22 de Abril, o art. 38ํe é dedicado ao livro de reclamações. De facto, o n. 1 do referido artigo refere que os serviços e organismos da Administração Pública "ficam obrigados a adoptar o livro de reclamações nos locais onde seja efectuado atendimento ao público, devendo a sua existência ser divulgada aos utentes de forma visível". No entanto, o n.ำ 8 do mesmo artigo refere que o modelo do livro a adoptar seria definido por portaria do Governo, a qual apenas foi publicada em Julho de 2006 (Portaria n.. 659/2006 de 3 de Julho). Ainda assim, há a salientar que $78 \%$ dos municípios respondeu que possuía, à data, livro de reclamações, demonstrando que os dirigentes e gestores de topo dos municípios reconhecem valor e pertinência à sua adopção como meio de recolha de informação e que tiveram, neste tocante, iniciativa, mesmo na ausência da regulamentação.

Quando questionadas quanto ao número de reclamações recebidas por mês, a maioria das autarquias refere que se trata de um número irrisório (na maioria dos casos apenas uma), sendo de salientar que $37 \%$ dos municípios não responderam a esta questão. Não obstante, quando inquiridos sobre se as reclamações efectuadas conduziram a melhorias de serviço prestados, 56 dos 71 municípios que responderam à questão indicaram que de facto as reclamações conduziram a melhorias nos serviços.

Da análise dos dados recolhidos no inquérito, pode-se ainda constatar que $62 \%$ dos municípios reconhece que não realiza qualquer avaliação da satisfação dos seus clientes.

Finalmente, no âmbito da interacção com o cliente, não pode ser descurado o modo como as autarquias lidam com eventuais reclamações e pedidos de informação. De facto, vários estudos provam que, se prontamente solucionadas (isto é, conseguida a "recuperação de serviço" (Soteriou e Chase, 1998)) muitas destas situações não influenciam negativamente a satisfação dos clientes. O inquérito revela que em $70 \%$ dos casos são os superiores hierárquicos dos municípios que se envolvem no tratamento de reclamações, sendo que em 93\% das situações é dada resposta aos clientes, oralmente, por ofício, fax, ou e-mail.

\begin{tabular}{l|c|c|c|c}
\hline Tabela 8 - Análise comparativa da interacção com o cliente & \multicolumn{3}{|c}{ MQUAL } \\
\hline \multirow{2}{*}{ Parâmetro } & GLOBAL & MSEM & NAOC & CERT \\
\hline Identificação das necessidades dos clientes & $68 \%$ & $64 \%$ & $69 \%$ & $68 \%$ \\
\hline Caixa de sugestões & $41 \%$ & $31 \%$ & $43 \%$ & $50 \%$ \\
\hline Livro de reclamações & $78 \%$ & $76 \%$ & $77 \%$ & $84 \%$ \\
\hline Comunicação abrangente & $17 \%$ & $11 \%$ & $26 \%$ & $18 \%$ \\
\hline Medição da satisfação & $33 \%$ & $11 \%$ & $30 \%$ & $67 \%$ \\
\hline
\end{tabular}

Por outro lado, como se observa na Tabela 8, se a identificação das necessidades dos munícipes ocorre na maioria das câmaras, sobretudo por via da utilização de caixas de sugestões e questionários, já a comunicação abrangente (a todos os colaboradores) dos principais resultados e informações obtidas é uma raridade. Nas autarquias que implementam referenciais de qualidade esta prática é ainda assim um pouco superior, eventualmente decorrente de uma cultura e estrutura organizacional mais favorável à comunicação interna e ao envolvimento de todos os colaboradores na solução dos problemas. É, no entanto, relativamente à medição da satisfação dos clientes que as câmaras que implementam a qualidade mais se distinguem das restantes. Efectivamente, sobretudo se o referencial de aplicação for a ISO 9000 , a medição regular da satisfação é um requisito da própria norma. 


\subsection{Governo Electrónico}

Da análise efectuada aos 308 municípios, como se descreve na Tabela 9, há a referir que 24 câmaras (i.e. 7,7\%) não possuíam em final de 2006 um site na Internet e 31 (i.e. 10\%) apresentavam a página indisponível. Assim, 55 municípios foram classificados no nível 0 .

Atendendo aos critérios anteriormente apresentados, no nível 1 encontravam-se $43 \%$ das AL. Consequentemente, uma boa parte dos municípios apenas divulga nas suas páginas internet informação genérica sobre os serviços.

O nível 2 foi atribuído a $27 \%$ dos municípios, ou seja, 104 municípios no universo dos 308 analisados permitem fazer o download de formulários e respectivas instruções de preenchimento.

Como referido antes, o nível 3 implica que exista a possibilidade de solicitar a prestação de um serviço através da Internet, ficando o munícipe/utente sujeito a um processo de registo como cliente (e posterior validação) antes de o processo dar entrada nos serviços da autarquia. Foram também incluídos neste nível os municípios que permitiam nos sites a consulta de processos e ofereciam atendimento online. Neste nível foram classificados 37 municípios, o que representa $12 \%$ do universo.

Apenas um município permitia à data do estudo efectuar por completo uma transacção online.

\begin{tabular}{l|c|c}
\hline Tabela 9 - Níveis de implementação do Governo Electrónico & \\
\hline Níveis & Número de Municípios & (\%) \\
\hline Nível 0 (site não disponível) & 31 & 10 \\
\hline Nível 0 & 24 & 7,7 \\
\hline Nível 1 & 133 & 43 \\
\hline Nível 2 & 82 & 27 \\
\hline Nível 3 & 37 & 12 \\
\hline Nível 4 & 1 & 0,3 \\
\hline
\end{tabular}

Relativamente aos municípios que participaram no inquérito (isto é, os 115 que têm vindo a ser descritos), constata-se que genericamente o nível de implementação do Governo Electrónico é um pouco superior ao nível médio nacional. Efectivamente, como descrito na Tabela 10, destes só uma reduzida faixa não utilizava a página da Internet para divulgar informação sobre a câmara ou prestar qualquer tipo de serviço online. Em particular, a proporção dos que apresentavam já num nível de maturidade elevado (3 ou 4) era de 16\%, acima da média global de $12 \%$ referida anteriormente. É ainda de destacar que são os municípios que implementam referenciais da qualidade (e em especial com serviços certificados) que apresentam um maior maturidade nas suas iniciativas de Governo Electrónico.

\begin{tabular}{|c|c|c|c|c|}
\hline \multirow{2}{*}{ Maturidade } & \multirow{2}{*}{$\begin{array}{c}\text { TOTAL } \\
\text { DOS INQUIRIDOS }\end{array}$} & \multirow{2}{*}{ MSEM } & \multicolumn{2}{|c|}{ MQUAL } \\
\hline & & & NAOC & CERT \\
\hline Nível 0 & $13(11 \%)$ & $8(21 \%)$ & $2(5 \%)$ & $3(11 \%)$ \\
\hline Nível 1 & $46(40 \%)$ & $15(40 \%)$ & $16(41 \%)$ & $10(35 \%)$ \\
\hline Nível 2 & $38(33 \%)$ & $13(34 \%)$ & $14(36 \%)$ & $6(21 \%)$ \\
\hline Nível 3 & 17 (15\%) & $2(5 \%)$ & 7 (18\%) & $8(29 \%)$ \\
\hline Nível 4 & $1(1 \%)$ & $0(0 \%)$ & $0(0 \%)$ & $1(4 \%)$ \\
\hline
\end{tabular}


A Tabela 11 faz uma síntese dos principais resultados do estudo empírico realizado, nomeadamente comparando o perfil de modernização administrativa dos municípios que implementam pelo menos um referencial de Gestão da Qualidade com aqueles que o não fazem. Para avaliar a significância estatística das diferenças foram realizados testes de Fisher, recomendados quando as variáveis a analisar são binárias e as amostras são de dimensão relativamente reduzida. São igualmente apresentados os valores dos Qui-quadrados de Pearson.

\section{Tabela 11 - Avaliação estatística dos relacionamentos Qualidade - Modernização}

\section{Administrativa}

\begin{tabular}{|c|c|c|c|c|c}
\hline Administrativa & \multicolumn{2}{|c|}{ MSEM } & \multicolumn{2}{c|}{ MQUAL } & \multirow{2}{*}{$\begin{array}{c}\text { Relevância estatística } \\
\text { da relação }\end{array}$} \\
\cline { 2 - 5 } Parâmetro & SIM & NÃO & SIM & NÃO & da relann
\end{tabular}

$\begin{array}{lllll}\text { Zona de atendimento } & 23 & 15 & 60 & 7\end{array}$

प日四

Fisher pvalue $=0,0009$

Pearson's chi-square $=12,234$

\begin{tabular}{llllll}
\hline Horário Contínuo & 16 & 22 & 34 & 33 & $\begin{array}{c}- \\
\text { Fisher pvalue }=0,4227\end{array}$
\end{tabular}

Pearson's chi-square $=0,726$

\begin{tabular}{|c|c|c|c|c|c|}
\hline $\begin{array}{l}\text { Identificação dos funcionários } \\
\text { do atendimento }\end{array}$ & 17 & 21 & 33 & 32 & $\begin{array}{c}- \\
\text { Fisher pvalue }=0,6832 \\
\text { Pearson's chi-square }=0,3\end{array}$ \\
\hline
\end{tabular}

\begin{tabular}{llllll}
\hline $\begin{array}{l}\text { Identificação das necessidades } \\
\text { de formação }\end{array}$ & 36 & 2 & 62 & 4 & $\begin{array}{c}\text { Fisher pvalue }=1 \\
\text { Pearson's chi-square }=0,028\end{array}$ \\
\hline
\end{tabular}

\begin{tabular}{lcccccc}
\hline Avaliação da formação & 16 & 22 & 29 & 37 & $\begin{array}{c}\text { Fisher pvalue }=1 \\
\text { Pearson's chi-square }=0,033\end{array}$ \\
\hline $\begin{array}{l}\text { Identificação das necessidades } \\
\text { dos clientes }\end{array}$ & 25 & 14 & 44 & 20 & $\begin{array}{c}\text { Fisher pvalue }=0,6693 \\
\text { Pearson's chi-square }=0,237\end{array}$ \\
\hline Caixa de sugestões & 12 & 26 & 31 & 36 & $\begin{array}{c}\text { Fisher pvalue }=0,1547 \\
\text { Pearson's chi-square }=2,164\end{array}$ \\
\hline Livro de reclamações & 29 & 11 & 51 & 16 & $\begin{array}{c}\text { Fisher pvalue }=0,8184 \\
\text { Pearson's chi-square }=0,174\end{array}$ \\
\hline Comunicação abrangente & 4 & 34 & 15 & 52 & $\begin{array}{c}\text { Fisher pvalue }=0,1875 \\
\text { Pearson's chi-square }=2,302\end{array}$
\end{tabular}

\begin{tabular}{lllllll}
\hline Medição da satisfação & 4 & 32 & 27 & 33 & $\begin{array}{c}\text { Fisher pvalue }=0,006 \\
\text { Pearson's chi-square }=11,819\end{array}$ \\
\hline $\begin{array}{c}\text { Governo electrónico } \\
\text { (maturidade - níveis 3e 4) }\end{array}$ & 2 & 36 & 16 & 51 & $\begin{array}{c}\text { Fisher pvalue }=0,0157 \\
\text { Pearson's chi-square }=5,917\end{array}$ \\
\hline
\end{tabular}


A análise da referida Tabela permite concluir que a adopção de referenciais da qualidade está particularmente associada a um maior nível de modernização administrativa no que se refere à existência de zonas de atendimento, medição da satisfação dos clientes e à maturidade das iniciativas de Governo Electrónico. No que respeita à utilização de caixas de sugestões e à comunicação interna ampla da informação recolhida dos clientes, embora existam indícios de alguma associação com a implementação da qualidade, as relações não são estatisticamente significativas.

Assim, pode-se afirmar que as diferenças mais relevantes entre os municípios que adoptam e não adoptam referenciais da qualidade não residem tanto no cumprimento de requisitos legislativos estritos, mas estão fundamentalmente ligados a práticas mais qualitativas, como as de medição e comunicação, e a acções de natureza mais ou menos voluntária, como é o caso das iniciativas de Governo Electrónico.

\section{Conclusões e implicações do estudo}

Da análise do discurso que tem presidido às iniciativas de Modernização Administrativa na generalidade dos países e do espírito da legislação que a, esse respeito, tem sido publicada, constata-se que a Qualidade, como filosofia de gestão, é entendida como essencial para tornar as Administrações Públicas mais eficazes, eficientes e, sobretudo, mais próximas dos cidadãos que servem.

Assim, assente na revisão da literatura efectuada, foi proposto neste artigo um modelo de análise que postula uma relação positiva entre a implementação de referenciais da qualidade e a Modernização Administrativa, aferida em duas vertentes: o cumprimento de um conjunto de requisitos chave do DL. n. $\stackrel{0}{135 / 99}$ e a maturidade das iniciativas de Governo Electrónico.

Dos dados obtidos, através de um questionário especialmente desenvolvido para o efeito e administrado a todos os municípios portugueses e da consulta dos respectivos sites institucionais, pode-se afirmar que, se por um lado o nível de implementação de alguns instrumentos de adesão voluntária (como a certificação e, até certo ponto, o próprio Governo Electrónico) é já significativa, existem mecanismos estabelecidos sob a forma de lei, mormente no Decreto-Lei de Modernização Administrativa, que não estão ainda a ser cumpridos, mesmo pelas autarquias que praticam a Gestão da Qualidade. A percentagem de incumprimento é particularmente elevada no que se refere ao funcionamento do horário contínuo e mesmo à identificação correcta de todos os funcionários.

Adicionalmente, são visíveis as limitações dos municípios na adopção de práticas de auscultação, medição e comunicação. Estas limitações revelam-se nos níveis ainda reduzidos de avaliação da formação dos funcionários, medição regular da satisfação dos clientes e reflexão interna alargada sobre as necessidades e opiniões dos munícipes. Acresce que permanece nalguns casos a convicção simplista de que é suficiente ter implementado um determinado mecanismo para que ele produza resultados, sem que se dê suficiente atenção à sua divulgação e efectiva utilização. O caso das reclamações é, neste tocante, muito elucidativo. $\mathrm{Na}$ generalidade, como indica o estudo realizado por Sá (2002), as autarquias vêem como suficiente a existência formal de um livro de reclamações, enquanto os cidadãos/utentes duvidam da sua real eficácia e tendem a não utilizá-lo. A menos que se trabalhe no sentido de incutir confiança e credibilidade no mecanismo formalmente existente, a sua eficácia será sempre reduzida.

Como se perspectivava, existem algumas diferenças significativas entre as autarquias que implementam referenciais da qualidade, mormente as normas ISO, e aqueles que o não fazem. Tal verifica-se, sobretudo, nas práticas de auscultação dos munícipes, medição da qualidade de serviço, divulgação dos resultados e envolvimento dos funcionários na resolução de problemas, as quais estão ligadas de forma próxima aos princípios da GQT.

Do estudo empírico realizado, resultam algumas oportunidades de melhoria que podemos traduzir nalgumas recomendações: 
- Integrar um espaço de recolha de comentários/sugestões nos documentos de preenchimento obrigatório, de forma a proporcionar canais simples para que os cidadãos/clientes participem activamente na construção de um serviço público mais orientado para as suas necessidades;

- Contribuir para que os clientes conheçam melhor os mecanismos à sua disposição para se pronunciarem sobre os serviços utilizados, bem como prestar um feedback rápido e personalizado a todas as opiniões apresentadas, dando conhecimento do desencadeamento de eventuais medidas correctivas, no sentido de aumentar a percepção da eficácia dos mesmos.

- Comunicar a todos os colaboradores (e em especial aos do atendimento, dado serem estes que estão em contacto directo com os clientes e que deverão mais rapidamente ajustar o serviço prestado às suas necessidades) as informações e os resultados das várias auscultações feitas aos clientes; e

- Medir regularmente a satisfação dos clientes, pois só assim será possível aferir a eficácia das medidas implementadas e analisar o modo como todos (e cada um dos colaboradores) poderão melhor contribuir para o aumento da satisfação dos seus clientes.

Verifica-se, ao mesmo tempo, que, apesar da ainda relativa imaturidade de muitas iniciativas de Governo Electrónico (maioritariamente, os municípios utilizam os seus portais de uma forma ainda rudimentar, predominando a preocupação com a divulgação da informação em detrimento da interacção com o cliente e o relacionamento unidimensional em detrimento das transacções on-line), as AL têm aproveitado as vantagens proporcionadas pelas TIC para se aproximarem dos seus munícipes, tendência que se perspectiva acentuar-se.

Assim, se a constatação do ainda elevado grau de incumprimento de algumas disposições da Lei de Modernização Administrativa é aparentemente surpreendente, porquanto o cumprimento da lei é muitas vezes entendido como o patamar mínimo de exigência, é de destacar, pela positiva, o considerável interesse que a adopção de alguns referenciais da Qualidade tem suscitado, especialmente as normas ISO e a CAF. Perante este interesse, o incumprimento de disposições potencialmente mais simples poderá eventualmente explicar-se pela falta de notoriedade que o "mero" cumprimento ou não de determinada exigência legal acarreta, em comparação com a visibilidade externa que o ganho de um prémio ou a ostentação de uma "bandeira" de certificação traz.

Deste modo, e de acordo com os resultados deste estudo, é de esperar que a adopção da Qualidade, ao reforçar os mecanismos de acessibilidade, transparência e flexibilidade propostos pela Modernização Administrativa, seja uma estratégia eficaz de chegar a algumas das finalidades últimas dos processos de modernização administrativa e que se prendem com ganhos de eficácia e eficiência, melhoria da qualidade dos serviços prestados, mas também, e acima de tudo, incremento da qualidade da própria democracia. 


\section{Referências Bibliográficas}

Ancarani, A.; Capaldo, G. (2001) Management of standardised public services: a comprehensive approach to quality assessment, Managing Service Quality, 11, 5, 331-341.

Araújo, J. (2001) Improving public service delivery: the crossroads between NPM and traditional bureaucracy, Public Administration, 79, 4, 915-932.

Araújo, J. (1999) Hiearquia, mercado e networks: mudança institucional, controlo e avaliação ReiUnido, in Avaliação na Administração Pública, Instituto Nacional de Administração, 291-310.

Dale, B.G.; Cooper, C.; Wilkinson, A. (1997) Managing Quality \& Human Resources: A Guide to Continuous Improvement, Blackwell, Oxford, UK.

Diário da República, Legislação diversa.

Dewhurst, F.; Martinez-Lorente; Dale, B. (1999) TQM in public organisations: an examination of the issues, Managing Service Quality, 9, 4, 265-273

Flynn, N. (1997) Public Sector Management, Prentice Hall, Harvester Wheatsheaf, UK.

Frederickson, H. (1996) Comparing the reinventing government management with the new public administration, Public Administration Review, 56, 3, 263-270.

Gaster, L. (1995) Quality in Public services: Managers' Choices, Open University Press, Buckingham, UK.

Guyomarch, A. (1999) 'Public Service', ‘Public Management' and the 'Modernization' of French Public Administration, Public Administration, 77, 1, pp 171-193.

Hood, C. (1995) Emerging Issues in Public Administration, Public Administration, 73, Spring, 165-183.

Hyde, A. (1992) The proverbs of Total Quality Management: Recharting the Path to Quality Improvement in the Public Sector, Public Productivity \& Management Review, 16, 1, 25-37.

Jackson, P. (1995) Reflections on performance measurement in public service organizations, in Measures for Success in the Public Sector: a public finance foundation reader, editado por Peter M. Jackson, CIPFA, 1-18.

Lakhe, R.R.; Mohanty, R. P. (1995) Understanding TQM in service systems, International Journal of Quality \& Reliability Management, 12, 9, 139-153.

Lawton, A.; Rose, A. (1991) Organisation and Management in the Public Sector, Second Edition, Pitman, UK.

Löffler, E. (2005) Defining Quality in Public Administration, 13 ${ }^{\text {th }}$ NISPAcee Conference Proceedings, Riga, Letónia.

Mehra, S.; Hoffman, J.; Sirias, D. (2001) TQM as a management strategy for the next millennia, International Journal of Operations \& Production Management, 21, 5/6, 855-876.

Morgan, L.; Murgatroyd, S. (1994) Total Quality Management in the Public Sector - An international perspective, Open University Press, UK.

Nolasco, M. (2004) A evolução da qualidade na Administração Pública Portuguesa, Cadernos $B A D, 33-47$.

Parker, R.; Bradley, L. (2000) Organisational culture in the public sector: evidence from six organisations, The International Journal of Public Sector Management, 13, 2, 125-141.

Rago, W. (1996) Struggles in transformation: A study in TQM, leadership, and organizational culture in a government agency, Public Administration Review, 56, 3, 227-234. 
Robledo, M. A. (2001) Measuring and managing service quality; integrating customer expectations, Managing Service Quality, 11, 1, 22-31.

Rocha, J.A. Oliveira (2006) Gestão da Qualidade - Aplicação aos Serviços Públicos, Escolar Editora, Lisboa.

Sá, Patrícia M. (2002) Organisational Excellence in the Public Sector: With special reference to the Portuguese Local Government, PhD Thesis, Sheffield Hallam University, UK.

Silvestro, R. (2001) Towards a contingency theory of TQM in services: How implementation varies on the basis of volume and variety, International Journal of Quality \& Reliability Management, 18, 3, 254-288.

Soteriou, A.; Chase, R. (1998) Linking the customer contact model to service quality, Journal of Operations Management, 16, 4, 495-508.

Staes, P.; Thijs, N. (2005) Report on the State of Affairs of the Common Assessment Framework (CAF) after Five Years, EIPASCOPE, 3, 41-49.

Sureshchandar, G. S.; Rajendran, C.; Anantharaman, R. (2001) A holistic model for total quality service, International Journal of Service Industry Management, 12, 4, 378-412.

Swiss, J. (1992). Adapting TQM to Government, Public Administration Review, 52, 4, pp. 356-362.

Zeithalm, V. A.; Berry, L.; Parasuraman, A. (1988) Communication and Control Processes in the Delivery of Service Quality, Journal of Marketing, 52, Abril, 35-48. 